\title{
Retraction Note to: Contrast-enhanced ultrasound appearances of enhancement patterns of intrahepatic cholangiocarcinoma: correlation with pathological findings
}

\author{
Francesco Loria ${ }^{1} \cdot$ Giuseppe Loria $^{1} \cdot$ Salvatore Basile ${ }^{1} \cdot$ Giuseppe Crea $^{1} \cdot$ Luciano Frosina $^{2} \cdot$ Isidoro Di Carlo $^{3}$
}

Published online: 8 May 2019

(C) Italian Society of Surgery (SIC) 2019

\section{Retraction Note to: \\ Updates Surg (2014) 66:135-143 \\ https://doi.org/10.1007/s13304-014-0251-6 and \\ Updates Surg (2015) 67:329 \\ https://doi.org/10.1007/s13304-015-0326-z}

A previous Retraction Notice has been published for this article [1]. This is the current Retraction Notice and provides an update to replace the previous Retraction Notice [2].

The original article https://doi.org/10.1007/s13304-0140251-6 has been retracted upon request of the authors as it contains similarities with paragraphs of a previously published article, "Contrast-enhanced ultrasound of intrahepatic cholangiocarcinoma: correlation with pathological examination. H.-X. Xu et al. Br J Radiol 85:1029-1037 (2012)".

While Prof. Dott. Di Carlo gave verbal consent to the corresponding author to insert his name among the authors,
Prof. Dott. Di Carlo did not contribute in any way to the editing of the article and explicitly did not approve the publication.

\section{References}

1. Loria F, Loria G, Basile S et al (2014) RETRACTED ARTICLE: Contrast-enhanced ultrasound appearances of enhancement patterns of intrahepatic cholangiocarcinoma: correlation with pathological findings. Updates Surg 66:135. https://doi. org/10.1007/s13304-014-0251-6

2. Loria F, Loria G, Basile S, Crea G, Frosina L, Di Carlo I (2015) Retraction Note to: Contrast-enhanced ultrasound appearances of enhancement patterns of intrahepatic cholangiocarcinoma: correlation with pathological findings. Updates Surg 67:329. https ://doi.org/10.1007/s13304-015-0326-Z
The online version of the original article can be found under https://doi.org/10.1007/s13304-014-0251-6.

The online version of the previous retraction note can be found under https://doi.org/10.1007/s13304-015-0326-z.

Francesco Loria

francescoloria956@alice.it

1 Department of Radiology, PO Palmi, ASP 5 Reggio

Calabria, Via B Buozzi 112, CAP 89015 Palmi, RC, Italy

2 School of Medicine, University of Messina, Messina, Italy

3 Department of General Surgery, Hamad General Hospital, Doha, Qatar 